\title{
Horner's syndrome subsequent to minimally invasive video-assisted thyroidectomy in two patients
}

\author{
KEXIN MENG ${ }^{1}$, WEI TIAN ${ }^{2},{\text { ZHENYE } \text { LV }^{1} \text { and XIANGYANG SONG }}^{1}$ \\ ${ }^{1}$ Department of Thyroid Breast Surgery, Zhejiang Provincial People's Hospital, Hangzhou, Zhejiang 310014; \\ ${ }^{2}$ Department of Surgical Oncology, The Second Affiliated Hospital, College of Medicine, \\ Zhejiang University, Hangzhou, Zhejiang 310009, P.R. China
}

Received July 30, 2014; Accepted April 14, 2015

DOI: $10.3892 / \mathrm{ol} .2015 .3159$

\begin{abstract}
Horner's syndrome (HS), characterized by a combination of ptosis and miosis, is an uncommon complication of thyroid surgery, particularly in minimally invasive thyroid surgery. Two cases of HS were observed secondary to minimally invasive video-assisted thyroidectomy in the Department of Thyroid Breast Surgery of Zhejiang Provincial People's Hospital between August 2012 and July 2014. The two patients developed miosis and ptosis following total thyroidectomy; all symptoms had resolved at 1 and 11 months subsequent to surgery, respectively. HS has currently been reported secondary to numerous types of minimally invasive thyroid procedures. The literature was reviewed to identify cases of this iatrogenic complication secondary to each type of thyroidectomy and the possible injury mechanisms underlying the syndrome were summarized in the present study. In addition, factors that were associated with minimally invasive thyroidectomy, such as the limited endoscopic vision during the procedure, the retraction effect and the occurrence of thermal damage from the use of the harmonic scalpel, were emphasized. The present study concluded that close attention is required during minimally invasive thyroid surgery in order to avoid HS as a complication of the procedure.
\end{abstract}

\section{Introduction}

Horner's syndrome (HS), which was first described by Horner in 1869 , is a condition that is characterized by the triad of ptosis, miosis and anhidrosis (1). The occurrence of HS has previously been revealed to be associated with damage to the oculosympathetic pathway (OSP) (2), which is a component of the sympathetic nervous system that affects the eyes.

Correspondence to: Dr Xiangyang Song, Department of Thyroid Breast Surgery, Zhejiang Provincial People's Hospital, 158 Shangtang Road, Hangzhou, Zhejiang 310014, P.R. China E-mail: 20918301@zju.edu.cn

Key words: Horner's syndrome, minimally invasive thyroidectomy
Additional clinical symptoms of HS, including enophthalmos and vascular dilation, can also be observed subsequent to injury of the OSP.

Although neck surgery is a frequent iatrogenic cause of HS, thyroid surgery-associated HS is rare (3). A previous study reporting the occurrence of HS secondary to thyroidectomy mostly attributed the development of HS to conventional thyroidectomy (4).

Since the first study reporting the use of minimally invasive video-assisted thyroidectomy (MIVAT) in 1998 (5), this surgical procedure has been widely performed due to its satisfactory cosmetic result and the minor pain experienced by the patient (6). In the present study, the cases of two patients that developed HS subsequent to MIVAT are reported, and a review of the literature is performed to interpret the possible injury mechanisms that led to HS following thyroid surgery, particularly in minimally invasive thyroidectomy.

\section{Materials and methods}

Patients who underwent MIVAT between August 2012 and July 2014 at the Department of Thyroid Breast Surgery of Zhejiang Provincial People's Hospital (Hangzhou, Zhejiang, China) were retrospectively reviewed in the present study. The records were evaluated to determine the medical history, pathology and follow-up information of the patients.

In all patients, the surgical procedure was conducted using a gasless endoscopic method, with retractors maintaining the surgical space. The vessels were ligated using UltraCision Harmonic Scalpel (Ethicon Endo-Surgery, Inc., Blue Ash, Cincinnati, $\mathrm{OH}, \mathrm{USA}$ ) until the lobe was completely freed. The recurrent laryngeal nerve was checked prior to the removal of the thyroid lobe. Lymph node dissection was also performed using the UltraCision Harmonic Scalpel. All dissected tissue was extracted by gently drawing the tissue through a $1.5-\mathrm{cm}$ incision in the skin.

\section{Results}

A total of 416 patients received MIVAT between August 2012 and July 2014. Of procedures performed, 76 were lobectomy, 42 were total thyroidectomy, 51 were near-total thyroidectomy, 107 were lobectomy with central lymph node dissection 
Table I. Clinical characteristics of patients with Horner's syndrome.

\begin{tabular}{|c|c|c|c|c|c|}
\hline Patient & $\begin{array}{l}\text { Age, } \\
\text { years }\end{array}$ & Gender & Diagnosis & Surgical procedure & $\begin{array}{l}\text { Time to } \\
\text { resolution, months }\end{array}$ \\
\hline 1 & 30 & $\mathrm{~F}$ & Right papillary carcinoma & Total thyroidectomy + prophylactic CLND & 11 \\
\hline 2 & 43 & $\mathrm{~F}$ & Bilateral papillary carcinoma & $\begin{array}{l}\text { Total thyroidectomy + prophylactic } \\
\text { CLND + right parathyroid transplantation }\end{array}$ & 1 \\
\hline
\end{tabular}

F, female; CLND, central lymph node dissection.

Table II. Reported cases of Horner's syndrome related with thyroid surgery.

\begin{tabular}{|c|c|c|c|c|}
\hline First author (Ref.) & $\begin{array}{l}\text { Number of } \\
\text { patients, } \mathrm{n}\end{array}$ & Type of procedure & $\begin{array}{l}\text { Time to } \\
\text { resolution }\end{array}$ & Pathological diagnosis \\
\hline Kang et al (11) & 1 & RAET & NM & NM \\
\hline Lee et al (12) & 1 & RAET & NM & NM \\
\hline Rosato et al (13) & 1 & Conventional & NM & NM \\
\hline Italiano et al (14) & 1 & Conventional & 2 months & Multinodular goiter \\
\hline de Silva et al (15) & 1 & Conventional & 3 months & $\begin{array}{l}\text { Degenerating colloid } \\
\text { nodule }\end{array}$ \\
\hline Vilallonga et al (16) & 1 & Conventional (secondary) & No improvement & $\begin{array}{l}\text { Poorly differentiated } \\
\text { insular carcinoma }\end{array}$ \\
\hline Aslankurt et al (17) & 1 & Conventional & No improvement & Multinodular goiter \\
\hline \multirow[t]{3}{*}{ Harding et al (10) } & 2 & Conventional & $\begin{array}{l}\text { Partial resolution } \\
\text { in } 1 \text { patient; } \\
\text { no improvement } \\
\text { in } 1 \text { patient }\end{array}$ & $\begin{array}{l}\text { Papillary carcinoma and } \\
\text { medullary thyroid cancer, } \\
\text { respectively }\end{array}$ \\
\hline & 1 & OMIT & Partial resolution & $\begin{array}{l}\text { Parathyroid adenoma, } \\
\text { normal thyroid nodule }\end{array}$ \\
\hline & 3 & Conventional (secondary) & No improvement & Papillary carcinoma \\
\hline Tan et al (18) & 1 & OMIT & 3 months & Follicular carcinoma \\
\hline Lee et al (19) & 5 & Conventional & NM & Malignant \\
\hline Solomon et al (9) & 1 & Conventional & 15 months & Multinodular goiter \\
\hline Cozzaglio et al (3) & 1 & Conventional & 3 days & Basedow-Graves' disease \\
\hline González-Aguado et al (20) & 1 & Conventional & 5 months & Papillary carcinoma \\
\hline
\end{tabular}

RAET, robotic-assisted endoscopic thyroidectomy; OMIT, open minimally invasive thyroidectomy; NM, not mentioned.

(CLND) ,99 were total thyroidectomy with CLND, and 41 were near-total thyroidectomy with CLND. Among this population, HS was post-operatively identified in two female patients, aged 30 and 43 years old, who were diagnosed with right papillary carcinoma and bilateral papillary carcinoma, respectively. The two patients had undergone minimally invasive video-assisted total thyroidectomy and prophylactic central neck lymph node dissection (level VI). The patient with bilateral papillary carcinoma also underwent right parathyroid transplantation. The clinical characteristics of the patients are summarized in Table I.

The patient diagnosed with right papillary carcinoma demonstrated miosis and narrowing of the palpebral fissure on the right side on post-operative day one, and mecobalamin tablets were administered immediately; this course of medication was discontinued after one week as no improvement was observed. The symptoms gradually resolved over a period of 11 months subsequent to surgery. No other complications, such as hematoma, inflammation and vocal cord palsy, were detected in this patient. The second patient, who had been diagnosed with bilateral papillary carcinoma, complained of discomfort of the right eye on post-operative day three. Following an ophthalmic test, HS with the presentation of right miosis and ptosis was diagnosed. No clinical signs of hematoma or other complications were spontaneously detected, and all symptoms had improved 1 month later; no treatment was administered during this period.

Subsequent to a follow-up periods of 21 and 14 months, respectively, the two patients demonstrated no evidence of disease recurrence or reported any discomfort. 


\section{Discussion}

The occurrence of an iatrogenic cervical sympathetic lesion following thyroid surgery was first described by Kaelin in 1915 (7). Few cases have been reported since, and the majority of cases are associated with conventional thyroidectomy (8). To the best of our knowledge, there have been only 18 cases involving the development of HS as a complication of conventional thyroid surgery since 1993 (Table II) that have been reported in the literature $(3,9-20)$. Due to the development of surgical techniques over the previous two decades, cervical sympathetic damage has also been reported as a post-operative complication that develops subsequent to the completion of open minimally-invasive thyroidectomy and robotic-assisted endoscopic thyroidectomy (Table II).

The potential mechanisms underlying this complication may differ between certain surgical procedures. HS has been confirmed to be induced by direct injury of the cervical sympathetic pathway due to anatomical factors (9). The OSP at the C8-T2 level, where second-order neurons are located, demonstrates a notable association with iatrogenic injury. In this preganglionic segment, the fibers of OSP arise from white rami communicantes at the first thoracic segment and join with the sympathetic chain. The fibers then pass through the inferior and middle cervical ganglion and finally synapse in the superior cervical ganglion (2). The middle cervical ganglion (10) and its thyroid branches (3) lie adjacent to the inferior thyroid artery, which originates from the thyrocervical trunk. Due to the anatomical contiguity in this component, the OSP is continuously at risk of injury during the procedure of lobectomy. In addition, the inferior thyroid artery has been reported to supply the sympathetic chain, which can be affected due to ligation of this artery (9). Partial nervous dysfunction arises from this ischemic damage. Furthermore, an anatomical study has previously demonstrated that anastomosis occurs between the recurrent laryngeal nerve and the cervical sympathetic chain in certain individuals (21). Therefore, isolation and identification of the recurrent laryngeal nerve may also exert trauma on the sympathetic chain. Considering the aforementioned anatomical aspect, direct sympathetic nerve lesions resulting from extensive dissection or neurovascular manipulation are one core etiological factor that leads to iatrogenic HS. In addition to direct injury, post-operative compression of the OSP due to hematoma and inflammation is another underlying cause (10).

Since the present cases occurred subsequent to MIVAT, HS was also potentially attributed to a number of elements. Firstly, due to the limited space that restricts the freedom of endoscopy, the whole branches of certain vessels or nerves could not be completely observed from one endoscopic vision while manipulating the adjacent structure to avoid injury. Secondly, the necessity of exposure in minimally invasive surgical techniques means that the retraction effect cannot be disregarded while revealing the lateral gland and neighboring structure. It has been hypothesized that stretching of the carotid sheath may also result in minor neural trauma (22). Thirdly, ultrasonically activated (US) instruments possess the two advantages of cutting and coagulation, and play a significant role in minimally invasive thyroid surgery. Carlander et al reported nerve dysfunction induced by the local energy effect from US instruments in a rat model. This study also considered that the degree of nerve damage depended on the duration of heat exposure (23). It has also been revealed that higher rates of transient recurrent laryngeal nerve palsy occur subsequent to the use of US instruments compared with conventional techniques (24). According to such evidence, thermal damage from the harmonic scalpel during the surgical procedure is another possible cause of HS, particularly in patients with sympathetic anatomical variations.

In the present patients, transient HS occurred immediately subsequent to surgery. No signs of post-operative hematoma were found in either patient. Accordingly, the potential causes of HS in the present patients were considered, including pressure from retractors and heat damage from the use of the harmonic scalpel.

Damage to the cervical sympathetic pathway due to thyroid surgery is rare. However, the present study indicates that close attention is required during minimally invasive procedures while ligating vessels and isolating tissue using US instruments. Surgeons should be aware of the possible anatomical complexity of the OSP and the association between the pathway and adjacent structures.

\section{References}

1. Horner F: Über eine Form von Ptosis. Klin Monatsbl Augenheilkd 7: 193-198, 1869.

2. Reede DL, Garcon E, Smoker WR and Kardon R: Horner's syndrome: Clinical and radiographic evaluation. Neuroimaging Clin N Am 18: 369-385, 2008.

3. Cozzaglio L, Coladonato M, Doci R, Travaglini P, Vizzotto L, Osio M and Gennari L: Horner's syndrome as a complication of thyroidectomy: Report of a case. Surg Today 38: 1114-1116, 2008.

4. Leuchter I, Becker M, Mickel R, and Dulguerov P: Horner's syndrome and thyroid neoplasms. ORL J Otorhinolaryngol Relat Spec 64: 49-52, 2002.

5. Miccoli P, Berti P, Conte M, Bendinelli $\mathrm{C}$ and Marcocci C: Minimally invasive surgery for thyroid small nodules: Preliminary report. J Endocrinol Invest 22: 849-851, 1999.

6. Miccoli P, Berti P, Raffaelli M, Materazzi G, Baldacci S and Rossi G: Comparison between minimally invasive video-assisted thyroidectomy and conventional thyroidectomy: A prospective randomized study. Surgery 130: 1039-1043, 2001.

7. Kaelin W: Über Störungen von seiten des Halssympathicus bei einfacher Struma und im Anschluß an deren operative Behandlung. Dtsch Z Chir 134: 395-423, 1915.

8. Smith I and Murley RS: Damage to the cervical sympathetic system during operations on the thyroid gland. Br J Surg 52: 673-675, 1965 .

9. Solomon P, Irish J and Gullane P: Horner's syndrome following a thyroidectomy. J Otolaryngol 22: 454-456, 1993.

10. Harding JL, Sywak MS, Sidhu S and Delbridge LW: Horner's syndrome in association with thyroid and parathyroid disease. ANZ J Surg 74: 442-445, 2004.

11. Kang SW, Lee SC, Lee SH, et al: Robotic thyroid surgery using a gasless, transaxillary approach and the da Vinci S system: The operative outcomes of 338 consecutive patients. Surgery 146: 1048-1055, 2009

12. Lee J, Yun JH, Nam KH, Choi UJ, Chung WY and Soh EY: Perioperative clinical outcomes after robotic thyroidectomy for thyroid carcinoma: A multicenter study. Surg Endosc 25: 906-912, 2011.

13. Rosato L, Avenia N, Bernante P, De Palma M, Gulino G, Nasi PG, Pelizzo MR and Pezzullo L: Complications of thyroid surgery: Analysis of a multicentric study on 14,934 patients operated on in Italy over 5-years. World J Surg 28: 271-276, 2004.

14. Italiano D, Cammaroto S, Cedro C, Bramanti P and Ferlazzo E: Horner syndrome following thyroidectomy. Neurol Sci 32: 531,2011 
15. de Silva WD, de Soysa MS and Perera BL: Iatrogenic Horner's syndrome: A rare complication of thyroid surgery. Ceylon Med J 55: 136, 2010.

16. Vilallonga R, Fort JM, Mazarro A, Gonzalez O, Caubet E, Romero G and Armengol M: Postthyroidectomy Horner's Syndrome. Case Rep Med 2012: 316984, 2012.

17. Aslankurt M, Aslan L, Colak M and Aksoy A: Horner's syndrome following a subtotal thyroidectomy for a benign nodular goitre. BMJ Case Rep pii: bcr2013009907, 2013.

18. Tan C, Sidhu S, Sywak M and Delbridge L: Management of hyperfunctioning single thyroid nodules in the era of minimally invasive thyroid surgery. ANZ J Surg 79: 386-389, 2009.

19. Lee YS, Nam KH, Chung WY, Chang HS and Park CS Postoperative complications of thyroid cancer in a single center experience. J Korean Med Sci 25: 541-545, 2010.

20. González-Aguado R, Morales-Angulo C, Obeso-Agüera S, Longarela-Herrero Y, García-Zornoza R and Acle Cervera L: Horner's syndrome after neck surgery. Acta Otorrinolaringol Esp 63: 299-302, 2012.
21. Reeve TS, Coupland GA, Johnson DC and Buddee FW: The recurrent and external laryngeal nerves in thyroidectomy. Med J Aust 1: 380-382, 1969.

22. de Quervain F: Weiteres zur Technik der Kropfoperation. Dtsch Z Chir 134: 475-520, 1915.

23. Carlander J, Johansson K, Lindström S, Velin AK, Jiang CH and Nordborg C: Comparison of experimental nerve injury caused by ultrasonically activated scalpel and electrosurgery. Br J Surg 92: 772-777, 2005

24. Hallgrimsson P, Lovén L, Westerdahl J and Bergenfelz A: Use of the harmonic scalpel versus conventional haemostatic techniques in patients with Grave disease undergoing total thyroidectomy: A prospective randomised controlled trial. Langenbecks Arch Surg 393: 675-680, 2008. 